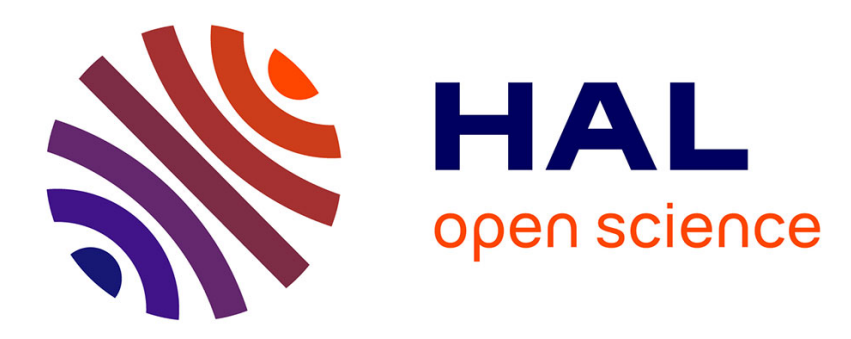

\title{
Inelastic neutron scattering study of solitons in CsNif3 in an external field
}

\author{
M. Steiner, J. Kjems
}

\section{To cite this version:}

M. Steiner, J. Kjems. Inelastic neutron scattering study of solitons in CsNif3 in an external field. Journal de Physique Lettres, 1978, 39 (24), pp.493-494. 10.1051/jphyslet:019780039024049300 . jpa00231553

\section{HAL Id: jpa-00231553 https://hal.science/jpa-00231553}

Submitted on 1 Jan 1978

HAL is a multi-disciplinary open access archive for the deposit and dissemination of scientific research documents, whether they are published or not. The documents may come from teaching and research institutions in France or abroad, or from public or private research centers.
L'archive ouverte pluridisciplinaire HAL, est destinée au dépôt et à la diffusion de documents scientifiques de niveau recherche, publiés ou non, émanant des établissements d'enseignement et de recherche français ou étrangers, des laboratoires publics ou privés. 
Classification

Physics Abstructs

$75.40-75.25-75.30 \mathrm{D}$

\title{
INELASTIC NEUTRON SCATTERING STUDY OF SOLITONS IN $\mathrm{CSNiF}_{3}$ IN AN EXTERNAL FIELD $(*)$
}

\author{
M. STEINER \\ Hahn-Meitner-Institut, Glienicker Straße 100, D-1000 Berlin 39, West Germany \\ and \\ J. KJEMS \\ Research Establishment Ris $\emptyset$, DK-4000 Roskilde, Denmark \\ (Reçu le 16 août 1978, révisé le 20 octobre 1978, accepté le 24 octobre 1978)
}

\begin{abstract}
Résumé. - Des expériences de diffusion inélastique des neutrons mettent en évidence une contribution appréciable des Solitons à la dynamique de spins de $\mathrm{CsNiF}_{3}$. Les champs extérieurs sont de 0 à $30 \mathrm{kG}$ et les températures de $5 \mathrm{~K}$ et $15 \mathrm{~K}$.
\end{abstract}

\begin{abstract}
By means of inelastic neutron scattering experiments it is directly demonstrated that $2 \pi$-Solitons contribute significantly to the dynamics of the 1-dimensional ferromagnet $\mathrm{CsNiF}_{3}$ in moderate external magnetic fields $(0-30 \mathrm{kG})$ and temperatures $(5 \mathrm{~K}-15 \mathrm{~K})$.
\end{abstract}

After the pioneering work of Krummhansl and Schrieffer showing the possible importance of kink solutions for the dynamics around a structural transition a lot of theoretical work has been done in this field [1], [2]. But up to now experimental evidence for the existence of Solitons is very rare. It was recently shown by Mikeska [3], that in a 1-dimensional ferromagnet with planar anisotropy Solitons should be observable in an external magnetic field.

$\mathrm{CsNiF}_{3}$ has been shown [4] to be a nearly ideal example of the model considered by Mikeska. Thus experiments were performed using a single crystal of $\mathrm{CsNiF}_{3}$, which contains only one isotope of $\mathrm{Ni}$ in order to reduce the background, at the DR-3 reactor in Ris $\emptyset$ on a triple axis spectrometer at the cold source.

The Solitons in this case are magnetic domains which move on the chains containing a field dependent number of spins. In spite of the fact that a direct excitation of these Solitons by neutrons is not possible, they are detectable in a neutron scattering experiment in the following way : the thermally excited Solitons behave like a gas of non-interacting particles, which have a certain velocity distribution. The neutrons are

$\left(^{*}\right)$ This paper has been presented at the LT 15 Conference as a post-deadline paper. scattered by these moving magnetic quasiparticles suffering energy changes due to a Doppler shift of the order of the typical kinetic energies of the Solitons. Thus the Soliton contribution to the scattering crosssection at low $q, q=0.1 \mathrm{r} .1$.u. is a quasi-elastic peak in addition to the usual magnon peaks. Due to the finite energy necessary to create a Soliton the intensity of the Soliton peak should exponentially increase with temperature with an activation energy given by the theory.

We performed inelastic neutron scattering experiments at $Q=(0,0,1.9)$, corresponding to $q_{\mathrm{c}}=0.1$ r.1.u., $0 \leqslant H \leqslant 5 \mathrm{kG}, 3.1 \mathrm{~K} \leqslant T \leqslant 14 \mathrm{~K}$. In figure 1 we show typical results for $H=5 \mathrm{kG}$ and different temperatures, which clearly show a steeply increasing central peak. The solid line is a theoretical curve, which has been least-squares fitted to the experiment. This curve contained the theoretical prediction for the Soliton contribution and two spin wave peaks all convoluted with the resolution function of the experiment and experimental correction factors such as transmission etc. From these fits we deduced the relevant parameters, which can be compared with the theoretical predictions. As a typical result we show in figure 2 the temperature dependence of the integrated intensity of the central peak on a semi-log-plot versus inverse temperature. 


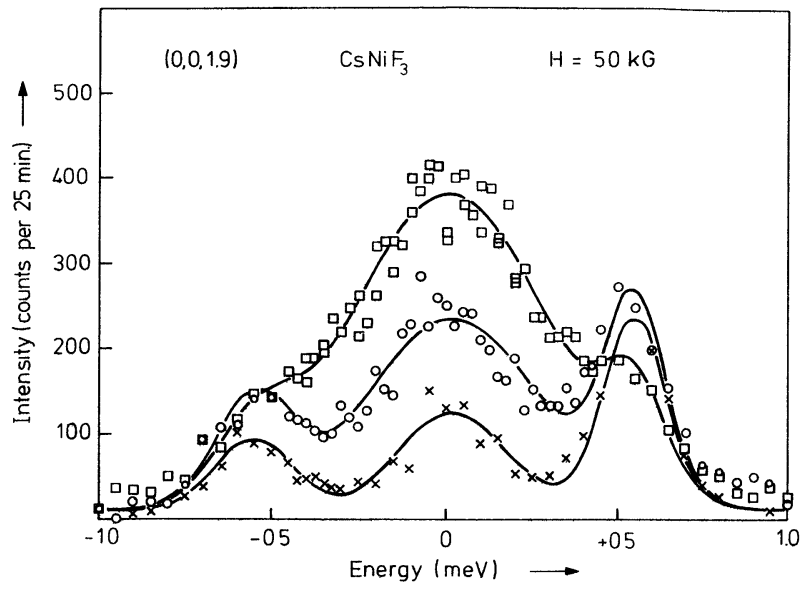

Fig. 1. - Experimental spectra for $Q=(0.0 .1 .9), H=5.0 \mathrm{kG}$ at $\times: 6.2 \mathrm{~K}, \bigcirc: 9.3 \mathrm{~K}, \square: 14 \mathrm{~K}$. The solid lines are fitted theoretical curves.

These data clearly show the exponential temperature dependence as expected for the Soliton peak for $T>5 \mathrm{~K}$. The activation energy $8 \mathrm{~m}$ as calculated is given by the solid line corresponding to $8 \mathrm{~m}=34 \mathrm{~K}$, whereas the experimental values yield (broken line) $8 \mathrm{~m}=27 \mathrm{~K}$. Similar results were found for the field dependence of the intensity. The width of the central peak agrees quantitatively with the calculated values.

To our knowledge, these experimental results give the most direct proof up to now for the existence and importance of such Solitons.

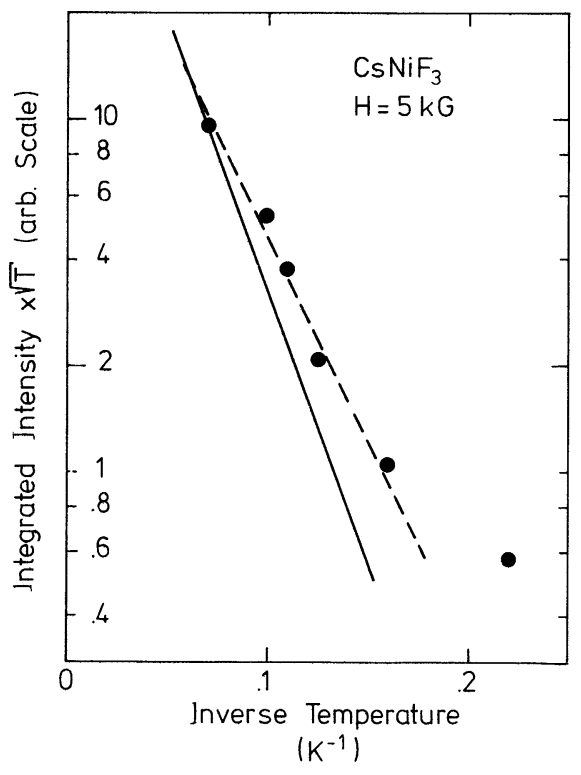

Fig. 2. - Semi-log-plot of the integrated intensity of the central peak versus inverse temperature; solid line : theoretical prediction scaled at $14 \mathrm{~K}$; broken line : best straight line through experimental points.

Finally it should be noted that the simplicity of the physical picture for the Solitons and the feasibility of the Soliton theory is due to the 1-dimensionality of the model used.

\section{References}

[1] Krummhansl, J. A., Schrieffer, J. R., Phys. Rev. B 113535.

[2] Guyer, R. A., Miller, M. D., Phys. Rev. A 17 (1978) 1205 ; Currie, J. F., Fogel, M. B., Palmer, F. L., Phys. Rev. A 16 (1977) 796.
[3] Mikeska, H. J., J. Phys. C 11 (1978) L-29.

[4] Steiner, M., Villain, J., Windsor. C., Adv. Phys. 25 (1976) 87. Steiner, M., Kuems, J., J. Phys. C 10 (1977) 2665. 